\title{
LOS JUEGOS DE LA RIMA EN UN POEMA DE JAIME SILES
}

\author{
JosÉ ENRIQUe MARTíneZ
}

Resumen: Este artículo revisa las referencias a la rima interna desde los primeros tratados de métrica a las métricas contemporáneas. En la poesía española actual es infrecuente el uso sistemático de la rima interna, por lo que se estudia y valora el empleo de dicho artificio en una composición extensa de Jaime Siles, no sin referirse a las etapas de su poesía y a la caracterización métrica de cada una de ellas.

Palabras clave: Rima interna, hemistiquios, "El oro de los días", encabalgamiento, recepción oral.

\begin{abstract}
This article goes through the references to internal rhyme from the first metric systems to the contemporary ones. The systematic use of internal rhyme is fairly infrequent in the current Spanish poetry, that is why we have focused our attention upon the use of this mechanism in an extensive composition by Jaime Siles. The stages of his poetry and the metric characterization of each of his poems have also been looked into.
\end{abstract}

Key words: Internal rhyme, hemistichs, "The gold of the days", enjambement, oral reception. 

La rima permite numerosos juegos, que han sido utilizados por los poetas unas veces con propósitos estilísticos, otras como puro divertimento. El más importante de todos ellos es el que sitúa la rima fuera del lugar esperado, con un posible efecto de extrañamiento ${ }^{1}$.

$\mathrm{F}$ UERA del lugar esperado se sitúa la rima interior o interna, que puede definirse como aquella "situada en lugar distinto del final de verso"2. La rima interna o "rima medial" como la llama Balbín ${ }^{3}$ es una práctica antigua que en nuestra lengua fue usada ya en la Edad Media "como adorno adicional para aumentar la sonoridad de los versos, enlazados ya por la rima final"". No tratamos aquí, sin embargo, de indagar en sus orígenes latinos y romances, sino de plantear algunas caracterizaciones históricas y actuales de la rima interna, con el fin de adentrarnos con mayores garantías en el análisis del uso de dicha rima en un poema concreto de un poeta contemporáneo.

Juan del Encina se refirió ya, como una de "las galas del trovar", a un tipo de rima interna que llamó multiplicado, "que es quando en un pie van muchos consonantes", como se aprecia en los dos versos que cita: "Dessear gozar amar / con amor, dolor, temor"5. Díaz Rengifo habla de "rima encadenada", la cual "se compone de versos, de tal manera

$\overline{1}$ MARCHESE, Angelo, y FORRADELLAS, Joaquín: Diccionario de retórica, crítica y terminología literaria. Tercera edición. Barcelona: Ariel, 1991, p. 353.

2 DOMINGUEZ CAPARRÓS, José: Diccionario de métrica española. Madrid: Alianza Editorial, 1999, p. 322.

3 BALBÍN, Rafael de: Sistema de rítmica castellana. Tercera edición. Madrid: Gredos, 1975, p. 247.

4 BAHER, Rudolf: Manual de versificación española. Madrid: Gredos, 1970, p. 74.

5 ENCINA, Juan del: Arte de poesía castellana, en López Estrada, Francisco (ed.), Las poéticas castellanas de la Edad Media. Madrid: Taurus, 1984, p. 92. 
eslabonados que el medio del uno vaya respondiendo siempre al fin del que pasó", distinguiendo dos tipos de "consonancia" según el hemistiquio con rima interna sea de cinco sílabas o de siete, caso este usado por Garcilaso de la Vega en su "Égloga II". Por su parte, Caramuel alude a los versos "concatenados" ("es un nombre usual entre los poetas españoles") porque "como en una cadena un eslabón está unido a otro por la mitad, así también sucede en estos versos: es decir, cuando en la cesura (de cualquier tipo que sea) la consonancia se encuentra"; distingue Caramuel dos tipos generales de rima interna: concatenación métrica ("se concatenan dos versos entre sí cuando el fin de un verso se corresponde con el final del hemistiquio siguiente", como en la citada "Égloga II" de Garcilaso) y concatenación estrófica (de dos estrofas, es decir, "cuando los versos centrales de una consuenan con los versos extremos de la siguiente"). Conoce Caramuel los dos tipos de concatenación de versos que distingue Díaz Rengifo, pero el precisa hasta siete tipos, según la cesura (donde "la consonancia se encuentra") caiga tras la primera, segunda, tercera, cuarta, quinta, sexta o séptima sílabas, es decir, según el hemistiquio rimado sea bisílabo, trisílabo, etc., y aún propone otras posibilidades combinatorias con sus esquemas métricos precisos ${ }^{7}$.

En el siglo XVIII Luzán, que defiende la rima espontánea y natural frente a la rima esforzada, llama rimas "eslabonadas" a las rimas internas, que son "las que, colocadas dentro de un verso, corresponden a la última palabra del verso antecedente", y aunque señala el inevitable ejemplo de Garcilaso, distingue tantas clases como Caramuel, según la sílaba donde ocurra la rima ${ }^{8}$.

Las métricas contemporáneas aluden, naturalmente, a la

- DÍAZ RENGIFO, Juan: Arte poética española. Facsímil de la primera edición de 1606. Madrid: Servicio de Publicaciones del Ministerio de Educación y Ciencia, 1977, pp. 91-92.

7 CARAMUEL, Juan: Primer Cálamo. Tomo II: Rítmica. Valladolid: Universidad de Valladolid, 2007, pp. 160-165.

8 LUZÁN, Ignacio de: La poética o reglas de la poesía en general y de sus principales especies. Edición de Russell P. Sebold (primera edición: 1737). Madrid: Cátedra, 2008, pp. 433-435. 
rima interna y sus diferentes clases. Así por ejemplo, Baher menciona las dos clases más frecuentes histórica y cualitativamente: en primer lugar la empleada por los trovadores provenzales, que fue usada en la Edad Media española "como adorno adicional para aumentar la sonoridad de los versos", pero de modo que las rimas internas de los hemistiquios eran independientes de las finales; en segundo lugar la usada en el Renacimiento y Siglos de Oro, cuyo modelo fueron los italianos, modalidad en la cual rima el final de un verso con el fin del hemistiquio del siguiente, que aparece por vez primera en España con la garcilasiana "Égloga II" que todos los tratadistas parecen tener en la cabeza cuando se habla de rima interna 9 . Por su parte, Domínguez Caparrós alude a tres tipos de rima interna: rima entre el final de verso y el final del hemistiquio del verso siguiente, rima independiente de todos los hemistiquios por un lado y de todos los finales de verso por otro $y$, finalmente, el uso de rimas internas sin un orden simétrico ${ }^{10}$.

La rima interna ha recibido valoraciones positivas y negativas. Luzán ya advertía que "si se hace por arte, es una de las variedades de la rima; pero si por inadvertencia y sin arte, se tiene por defecto", añadiendo que las rimas "vecinísimas" como las que Juan del Encina llamó "multiplicado" y que tuvo por gala de la poesía "no es sino un enfadosísimo sonsonete y un juego pueril"11. Navarro Tomás y Oldřich Bělič comentan unos versos de Unamuno con rima interior no simétrica que valoran positivamente, pues para el primero "Unamuno prescindió del carácter regular y mecánico de esta antigua práctica, aplicándole con mayor libertad y eficacia expresivas"12; por su parte, Bělič habla de "una instrumentación fónica muy llamativa y muy eficaz" y de "una extraordinaria carga y densidad semánticas", y piensa que, si

BAHER, Rudolf: Manual de versificación española, cit., pp. 73-75.

10 DOMÍNGUEZ CAPARRÓS, José: Diccionario de métrica española, cit., pp. 332-333.

11 LUZÁN, Ignacio de: La poética, cit., pp. 434-435.

12 NAVARRO TOMÁS, Tomás: Métrica española. Reseña histórica y descriptiva. Cuarta edición (primera edición: 1956). Madrid-Barcelona: Guadarrama, 1974, p. 465 . 
se trata de rima interna, puede ser "una réplica provocativa de la práctica corriente de las rimas interiores"13. Rafael de Balbín valora así la que él llama rima medial: "El efecto de relevación que nace de la rima, sobrevalora la pausa interna, y prefigura un segundo axis estrófico, que, aunque impreciso y difuso, perturba ostensiblemente el concierto rítmico de la estrofa" ${ }^{14}$. Luis Mario rechaza las asonancias internas -como lo hacían los tratadistas anteriores, como Eduardo Benotpero no las consonancias, porque "en este caso se advierte la intención del poeta, siempre a la caza de lo bello", y añade, tras los ejemplos oportunos: "Las consonancias internas son eufónicas siempre que no se abuse de ellas"15.

Algunos tratadistas advierten sobre los peligros de la rima interna. Rudolf Baher señala que, en los casos de rimas internas de los hemistiquios entre sí, independientes de las rimas finales, se pone en peligro la unidad del verso ${ }^{16}$. Lo mismo indica Domínguez Caparrós, extendiendo el peligro al uso de la rima interna de forma simétrica, mientras que en su uso no simétrico "produce un contraste que da variedad al ritmo"17; Domínguez Caparrós pone el acento en el carácter eufónico, más que rítmico, de la rima interna, pues si nunca se puede prescindir de tal carácter al tratar de las rimas, cuando éstas se sitúan fuera del final de verso, "no tienen una función estrictamente métrica, en el sentido de reforzar la percepción de un esquema de número de sílabas determinado"18.

Si en cualquier poema, advertida o inadvertidamente, pueden aparecer rimas internas esporádicas, no es frecuente en la poesía contemporánea el uso mecánico y simétrico de tal

13 BĚLIČ, Oldřich: Verso español y verso europeo. Introducción a la teoría del verso español en el contexto europeo. Santa Fe de Bogotá: Publicaciones del Instituto Caro y Cuervo, 2000, p. 207.

14 BALBÍN, Rafael de: Sistema de rítmica castellana, cit., p. 248.

15 MARIO, Luis: Ciencia y arte del verso castellano. Miami: Ediciones Universal, 1991, pp. 115-116.

16 BAHER, Rudolf: Manual de versificación española, cit., p. 74.

17 DOMÍNGUEZ CAPARRÓS, José: Diccionario de métrica española, cit., p. 334.

18 DOMÍNGUEZ CAPARRÓS, José: "La rima: entre el ritmo y la eufonía", en Estudios de métrica. Madrid: Universidad de Educación a Distancia, 1999, p. 155 . 
procedimiento. De ahí que me llamara la atención tal empleo de la rima interna en una composición relativamente extensa de Jaime Siles, "El oro de los días", con la que se inicia Himnos tardios (1999), que consta de ochenta y nueve versos. Pero antes de abordar métricamente el poema, trazaremos con brevedad algunas coordenadas de la poesía del autor.

El propio Siles ha discernido lúcidamente la evolución de su poesía ${ }^{19}$. En un acercamiento inicial al conjunto de la misma nos servimos de las apreciaciones del poeta, que contempla tres etapas sucesivas: $1^{\text {a }}$ ) Excluida, escribe el poeta, "una breve temporada irracionalista" que se vertió en Génesis de la luz (1999), esta etapa primera comprende los tres libro siguientes: Canon (1973), Alegoría (1977) y Música de agua (1983), siendo este último el más minimalista de sus libros, participando tanto de la metapoesía como de la poética del silencio; con las naturales diferencias entre ellos, los tres participan de un rasgo común, "la economía del lenguaje" y su consecuencia visual: el poema breve con cierta similitud formal y con algunas manifestaciones de la poesía pura, aspectos que diferencian la poesía de Siles de la de su generación. Otros rasgos comunes: la idea de sistema que rige cada libro, pues cada poema se explica en función de la estructura, lenguaje y estilo del poemario en que aparece, y "la anulación elocutiva del yo del poema", tendente a la representación objetiva y a la separación del intimismo que caracterizó a la generación anterior (la del cincuenta); 2a) Entre 1982 y 1989 transcurre la segunda etapa, que comprende cuatro libros: Columnae, Poemas al revés, El gliptodonte y otras canciones para niños malos y Semáforos, semáforos. Según aclara el autor, el cansancio del intelectualismo que caracterizó a la etapa anterior, el redescubrimiento de la naturaleza y ciertas circunstancias biográficas provocan el cambio hacia una formalización distinta de unos temas que podían no haber variado tanto; tal formalización supone apoyarse en el mundo sensible y objetivar la presencia real, el referente; métricamente predomina el metro, la estrofa y el verso clásicos; $3^{\mathrm{a}}$ )

19 SILES, Jaime: "El yo es un producto del lenguaje", en Poética y poesía. Madrid: Fundación Juan March, 2007, pp. 19-38. 
La última etapa la constituyen Himnos tardios (1999) y Pasos en la nieve (2004), libros a los que hay que agregar Desnudos $y$ acuarelas (2009) y Actos de habla (2009); refiriéndose a los dos primeros escribe el poeta que en ambos hay un lirismo existencial y un análisis del sujeto poético yo, no como prolongación del yo del poeta, sino creado por los poemas en ese preciso espacio ficcional; respecto a Himnos tardios -al que pertenece el poema que analizaremos- señala Siles que combina el himno con la elegía de estirpe germánica más que latina.

Desde el punto de vista métrico, nos atenemos de momento y sin ningún afán exhaustivo, a las dos primeras etapas de la poesía de Siles, las que preceden a la aparición de Himnos tardios, siguiendo la recopilación de su Poesía 1969-199020.

En la primera etapa poemas en verso libre que, cuando son largos, suelen participar de un ritmo endecasilábico o se trata de versículos reconducibles por división a versos de tal ritmo (pentasílabos, heptasílabos, endecasílabos, etc.), por lo que no es extraño el abundante uso de distintos tipos de silva libre (combinaciones de endecasílabos y alejandrinos y de tales versos con pentasílabos y heptasílabos) o de combinaciones tradicionales (pentasílabos y heptasílabos); hallamos, además, escasos poemas en prosa en Génesis de la luz y el inicial de Canon, que no son otra cosa, salvo excepciones, que una sucesión de heptasílabos y endecasílabos enmasca$\operatorname{rados}^{21}$, y poemas perfectamente regulares, también escasos, en endecasílabos blancos o rimados y en heptasílabos; hay que anotar, por otro lado, que la disposición gráfica es muchas veces el disfraz de una regularidad fácilmente perceptible, como ocurre en "Economía de los cambios nocturnos" (Música de agua), cuyos cuatro últimos versos descomponen gráficamente dos endecasílabos cabales, por lo que el poema oculta una regularidad métrica (cuatro endecasílabos) evidente:

20 SILES, Jaime: Poesía 1969-1990. Madrid: Visor, 1992.

21 Un ejemplo: "Este ir y venir por los rincones - de un cuerpo sin fronteras - es recorrer el hemisferio oculto - de las miradas frías-. En las manos más hondas de un verano sin luna -el horizonte tiembla". 
Sobre la luz delgada sólo puntos.

En el centro del iris sólo gotas, que la noche revierte

-punto o gota-

en el delgado centro

de la luz.

En cuanto a la rima - puesto que de la rima trataremos en un poema de Himnos tardios- puede decirse que, salvo casos de rima idéntica (un procedimiento más de reiteración fonosemántica) u ocasional (no buscada), sólo siete u ocho composiciones llevan rima, asonante en unos casos ("Eternidad del aire" y "Siesta", del cuaderno Biografia sola, de 1970), combinación de asonancia y consonancia en otros ("Equilibrio del agua", también de Biografía sola), o consonancia en determinados poemas de Música de agua, todos de la sección III, titulada "Grafemas": "Enigma", cuarteto más terceto (ABBA//CCA), "Recurrencias", cuarteto (ABBA: ti - agotas - gotas - ti), "Abanico", quinteto (AABAB: rosa - rosa - ves - cosa - revés), todos ellos formados por versos endecasílabos, más un poema de rara factura, "Disoluciones", combinación personal de endecasílabos, heptasílabos y alejandrinos con abundancia de rimas idénticas: letra - gota (endecasílabos) - ser - ser - blanco - ser // línea -ígnea - volver - ser (cuartetas heptasilábicas) - blanco - es - blanco -es (con alternancia de alejandrino y heptasílabo).

En esta primera etapa la métrica no deja de atenerse a ritmos esperables, a pesar de que la distribución gráfica apunte lo contrario en ocasiones, o de que el uso de versículos oculte la suma de versos canónicos; se muestra, eso sí, poco afecto a la rima.

La segunda etapa está "caracterizada por el predominio del metro, la estrofa y el verso clásico", ha escrito Siles ${ }^{22}$. Y así es, en efecto. Salvo rarísimas excepciones, se trata de versos regulares y rimados. En versos de arte menor es frecuente la forma de romance heptasilábico dispuesto en cuartetas; hay algún romance octosilábico, sonetillos, décimas, tercerillas,

22 SILES, Jaime: Poética y poesía, cit., p. 27. 
cuartetas octosilábicas y otras combinaciones; en versos de arte mayor hay liras, sonetos (uno de ellos en alejandrinos), algún romance heroico dispuesto en cuartetos, series de endecasílabos con rimas consonantes o con asonancias y consonancias mezcladas sin regularidad estrófica, etc., etc. Todo un alarde de ingenio que se muestra especialmente en los juegos con las rimas, no por el uso de alguna rima rara (en-Poussin, sé-Orsay-Monet, Guillaumet-Baudelaire-Gauguin...) o por la afición a la rima idéntica, sino principalmente por el sostenimiento de unas mismas rimas a lo largo de un buen número de versos o de toda una composición. En este sentido, los largos poemas endecasilábicos de las partes segunda y tercera de Semáforos, semáforos merecen un estudio especial que no es objeto de este trabajo, el cual se centra, por fin, en "El oro de los días", poema de Himnos tardíos (1999), un libro que -tras los juegos fónicos y los alardes de vario tipo de Columnae, a los que se añade en Semáforos, semáforos el coloquialismo y la versión poética de lo cotidiano, sin que falten muchas dosis de ingenio y humor- se decantó hacia la vida en toda su magnitud pensable. No faltan abstracciones, como en los libros de la primera etapa de Siles, pero las que hay provienen de un pensamiento denso sobre el vivir (tiempo, dolor, etc.), con sus simbolismos laberínticos colmados de reiteraciones y contrastes. En "El lugar del poema" entiende el poeta que las oscuridades posibles de la poesía proceden de la vida misma; no importa su perfección formal, sino su sentido vital, su capacidad de movernos transmitiéndonos una emoción intensa.

Métricamente, Himnos tardios ha moderado los juegos de versos y rimas de la etapa anterior. Sólo encontramos cinco composiciones rimadas: "El oro de los días" que después analizaremos, "Hay un viento sin hojas", en alejandrinos, en el cual los diez primeros versos riman en asonante agudo $-i$ los pares, mientras los siete últimos versos añaden a dicha rima aguda otra rima con mezcla de asonancia y consonancia: -ója (3 vv.), -ójas (un v.), -óza (un v.), "Pasos sobre el papel", en alejandrinos, los cuales riman todos en asonante -é, si bien los seis últimos forman, además, pareados consonánticos en -él, -én y -éz respectivamente, el último con rima idéntica 
(vez en los dos versos finales), "Memoria del disfraz", romance heroico en el que se deslizan dos dodecasílabos ("Burlé la muerte y, en vida, fui la nada. / Pido a Dios que si mi cuerpo resucita"), y "Divagación", romancillo heptasilábico distribuido en cuartetas.

Por lo demás, salvo los dos endecasílabos blancos que inician el libro y un par de silvas libres ("El lugar del poema" y "Ángulos muertos"), las demás composiciones van en verso libre, con fuerte tendencia hacia el ritmo endecasilábico, subrayado por la abundancia, entre versos amétricos, de versos canónicos como el endecasílabo y el heptasílabo.

De este modo, "El oro de los días", por la regularidad silábica y el mantenimiento de una misma rima a lo largo de la composición, es, métricamente, el puente de unión entre la segunda y la tercera etapa, algo subrayado, además, por su posición inicial, si obviamos los dos endecasílabos que le preceden. Cierra, por así decir, la etapa anterior y da entrada a otras formas de versificación más acordes con el marchamo reflexivo que Siles imprime a los poemas.

En "El oro de los días" un personaje en primera persona evoca los brillos de la juventud perdida. El poema se establece en un presente desde el que actúa la memoria (el verbo "recordar" cobra importancia capital por su recurrencia), una memoria que produce dolor al comprobar que aquel oro de los días, que nunca tornará, es hoy "ceniza". El poema tiene un recorrido reflexivo - de ahí las interrogaciones retóricas-y una tonalidad elegíaca.

"El oro de los días" se compone de 88 alejandrinos más un heptasílabo final, si bien este trabajo se limita al estudio de los juegos de la rima en el poema, principalmente de la rima interna:

EL ORO DE LOS DÍAS

Cuando, en mi memoria, la veo detenida en un brillo de espejos que reflejan la vida y que tal vez la fueron o lo son, qué perdida mi juventud resbala por el aire. Precisa espuma y ala y ola profundas en la brisa 
que yo no supe entonces y no sé todavía, pero recuerdo a veces. ¿Viví, viví: vivía?

Su dolor es quien dura dentro de mi sonrisa.

Es su dolor de acero, de zinc, de mordedura.

Es el dolor certero que deja su figura:

dolor de la memoria del oro de los días.

Dolor de haber creído vivir mientras leía.

Dolor de no haber sido y no ser todavía

y nunca poder serlo ni en una nueva vida.

Porque, después de todo, vivir, vivir -¿vivía?-

tiene sentido sólo en una sinfonía

¿y dónde los acordes; dónde, la melodía?

Recuerdo, sí, recuerdo el oro de los días:

la luz de sus mañanas metálicas y limpias;

el sol en las ventanas, en las torres y cimbrias;

el destello del cielo aquella tarde en Niza

y la forma del hielo, otra tarde, en Suiza.

Recuerdo que recuerdo, sobre todo, ceniza.

Recuerdo que recuerdo fragmentos de mi vida.

Pero ¿de quién: de otro, de mí, de ella misma?

Existe sin nosotros todo lo que nos mira.

Un dios pulsaba el aire y otro lo tañía.

Nevaba sobre el Néckar. Había también islas.

El nácar de la nieve redondo parecía.

Florecía en el malva de la carne. Tenía

resplandores de oro su lenta fronda fija.

Recuerdo que recuerdo sus murallas erguidas-

adarves de alabastro, dovelas opalinas.

Dolor de su recuerdo es esta despedida,

esta página vuelta del oro de los días.

Pero nosotros ¿dónde, en qué mirada fija

podremos apoyarnos para fundar la vida,

si todo su lenguaje ya no nos ilumina?

Palabras y palabras ganadas y perdidas.

Yo que amé su perfume, descubro las imágenes

de las que son ruina. Recuerdo, sí, palabras:

las palabras perdidas. Tal vez estaba en ellas, no en mí. Yo no sabía. En el nácar del Néckar veo el zinc de sus islas. Allí estaba, allí estuvo mi juventud perdida. Tú que me lees no sabes

dónde el texto termina. Las palabras empiezan a ser $-\mathrm{y}$ son- más vida. Paisaje de nosotros, paisajes de la vida, sus aguas son mensajes; sus luces, ocarinas. Recuerdo que recuerdo el oro de los días. Recuerdo que recuerdo 
su materia ya sida. Su memoria recuerdo: su carne fugitiva. Sus señales escucho: sus salvas suicidas. Olor de las tormentas de tantas tardes idas. Idas ya para siempre y para siempre sidas. En vosotras, mañanas de escritura lumínica, estaba ya la nieve del día diluida. ¡Qué cerámicas noches húmedas y distintas con su roce de sedas y faldas femeninas! Con su aliento profundo de velas derretidas y destellos de bares en sus luces fundidas. Neones de los cines en sus medias. Bebidas en sus labios. Los ojos con una idea fija. Duplicado deseo de serlo todavía, miro hoy los espejos de lo que fue mi vida. Azogada acuarela, iridiscente línea, ¿en qué país buscarte, móvil ciudad perdida? Tú nunca vuelves: tienes lugar en otros días, en otro tiempo y otro espacio sucedida. También en otro cuerpo, también en otro clima. En otro, sí, en otro su impermeable risa. Tú que me lees no sabes nada, no, de mi vida. El poema traduce experiencias vividas. Experiencias: visiones en la memoria sidas. Experiencias: canciones cantadas y leídas en el cuerpo del libro único de la vida. En este libro único tu página está escrita. Viviste allí las horas del oro de los días. Viviste y bebiste su líquida caricia. Sus imágenes vuelven en ráfagas precisas. Remuéveles su fondo de fresas y glicinias. El oro de los días vuelve hoy de visita. Tal vez es otro oro. Tal vez son otros días. El poema recoge las páginas perdidas: las que el cuerpo recuerda y el alma nunca olvida. Estrofas de la carne para siempre ya sida, el oro de las horas del cobre de los días. Estrofas de la carne, adiós. Adiós, mentiras de mi pobre moneda en curso todavía ${ }^{23}$.

La primera constatación es que todos los versos se ven afectados por la rima, excepto el 40, que sirve de transición entre los 39 alejandrinos anteriores, en que la rima se sitúa

23 SILES, Jaime: Himnos tardios. Madrid: Visor, 1999, pp. 15-17. 
en su lugar natural, a fin de verso, y los 49 que le siguen, con rima interna únicamente (con la excepción de los versos 7374, también con rima final diferente de la medial).

La segunda constatación es que en el conjunto del poema hay una asonancia única, - $i a$, tanto en final de verso como en el interior, con excepción de los versos 9-10, que riman en -úra (mordedura-figura) y la rima final de los versos 73-74, que lo hacen en -ónes (visiones-canciones). Pero este aserto requiere algunas matizaciones. Visto el poema como unidad, en su conjunto, todos los versos, con las excepciones indicadas de los versos 9-10, van trabados por una misma rima asonante en -ía, pero dentro del mismo, el poeta va uniendo determinados versos contiguos o próximos por consonancia. Es lo que ocurre de forma patente en los versos iniciales de la composición: AAA (-ida) BB (-ísa) CC (-ía) BDD (-ura) E (-ías) CCACCCE; los vv. 21-22-23 riman los tres en -íza. Y en lo que se refiere a la rima interna, los vv. 53-54-55 riman en -idas, al igual que los vv. 60-61-62 y los v. 73-74-75; y los vv. 65-67-69-72 lo hacen en -ida, al igual que los vv. 85-86. No importa tanto el que se trate de una rima fácil (participios en -ida) como el que incida en aspectos semánticos esenciales en el poema, que trata de la constatación de la vida (juventud) perdida, finiquitada o sida. Es difícil que en un poema largo que reitera una misma rima en casi todos sus versos no haya reiteración también de palabras en posición de rima, máxime tratándose de un poeta que no ha desdeñado la rima idéntica en buen aparte de sus composiciones rimadas. En situación de rima, la palabra vida aparece nueve veces en el poema: de ellas, por su cercanía, puede considerarse idéntica la rima de los versos 47-48; dicha palabra vida, que aparece ya en el segundo verso rimando con perdida (con el plural, perdidas, seis ocurrencias en posición de rima), percute en el ánimo del lector a lo largo del poema, como lo hace días (siete ocurrencias en posición de rima) o sida, participio de "ser" (con su plural sidas, con cuatro ocurrencias como rima interna).

Rima y pausa versal colaboran en la definición y percepción del verso como unidad de sentido. En los casos de encabalgamiento la ejecución o reiteración puede mantener el 
ritmo métrico, con pausa versal marcada, por breve que sea, o el ritmo sintáctico, siguiendo el desarrollo de la frase. En cambio, en los versos esticomíticos la rima final colabora en la percepción sonora de la unidad rítmica versal, como ocurre en la primera parte de "El oro de los días" (los 39 versos primeros), con rima en final de verso y una pronunciada esticomitia (en realidad sólo hay encabalgamiento versal en los versos iniciales: qué perdida / mi juventud, precisa / espuma, la brisa / que yo no supe...), subrayada gráficamente por diferentes signos de puntuación (en 27 de los 39 versos). Es más frecuente el encabalgamiento interior entre hemistiquios (nueve casos), pero salvo pronunciación enfática, siempre menos o apenas perceptibles. La conclusión es que Siles tiende a delimitar métrica y rítmicamente la unidad versal mediante la pausa y la rima.

Otro caso es la rima interior de la segunda parte del poema, es decir, de los 49 versos últimos. Se sitúa siempre al final del primer hemistiquio; por lo tanto, los primeros hemistiquios riman todos entre sí en asonante $-i a$, a la vez que con los finales de los 39 versos primeros del poema. Pero la impresión es que se trata de un mero artificio formal. En una ejecución oral, en una recitación, percibiríamos la rima interna como final de verso por varias razones: primeramente por la inexistencia de encabalgamiento entre hemistiquios (sólo existe uno, en el penúltimo verso: mentiras / de mi pobre...); en segundo lugar porque en altísima proporción (en 37 de los 49 versos) la pausa intermedia entre hemistiquios, o pausa en el interior de versos compuestos como llama Domínguez Caparrós $^{24}$ a lo que otros llaman cesura (Quilis) y otros cesura intensa (Baher), va marcada gráficamente por un signo como el punto, que ortográficamente es el que indica la pausa sintáctica mayor; en tercer lugar porque tal pausa indica que la unidad de sentido la componen el segundo hemistiquio de un verso y el primero del siguiente. En la ejecución oral de los versos, lógicamente, la pausa mayor coincidiría con la pausa intermedia, relevada además por la rima, lo que implicaría la

${ }^{24}$ DOMÍNGUEZ CAPARRÓS, José: Métrica española. Madrid: Síntesis, 1993, p. 102. 
percepción de la rima interna como rima final de verso. Téngase en cuenta, además, que, frente a la casi total ausencia de encabalgamiento entre hemistiquios, es frecuente el encabalgamiento versal en esta segunda parte del poema, con la consiguiente aminoración de la pausa versal y, por lo dicho, la potenciación de la pausa intermedia entre hemistiquios. Otro hecho que se debe tener en cuenta es la terminación del poema con un heptasílabo que, en la marcha del poema, correspondería a un primer hemistiquio de un alejandrino al que se le ha hurtado el segundo; pero en la recepción oral, con factores de tanta importancia rítmica como la entonación (gráficamente es otra cosa) tal hecho conlleva la potenciación en toda la serie del primer hemistiquio, percibido como final de verso.

Estas consideraciones nos permiten retornar a las páginas iniciales de este trabajo para concluir que en casos como "El oro de los días", las rimas interiores entre los primeros hemistiquios de los alejandrinos no sólo ponen en peligro la unidad del verso, como señalan Baher y Domínguez Caparrós, sino que, al menos en la recepción oral, trasladan la sensación del final de verso al fin del primer hemistiquio. En cualquier caso parece claro que adorno, divertimento y artificio se han sumado en los juegos de la rima de "El oro de los días". 